\title{
Low-Cycle-Fatigue Behavior of Copper Materials and Their Use in Synchrotron Beamline Components
}

Zhibi Wang, Tom Nian, David Ryding, and Tuncer M. Kuzay

\author{
Experimental Facilities Division \\ Advanced Photon Source \\ Argonne National Laboratory \\ '9700 South Cass Avenue \\ Argonne, IL 60439
}

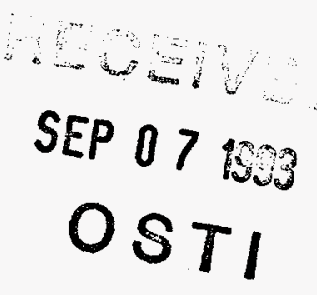

\section{Introduction}

The third generation synchrotron facilities such as the 7-GeV Advanced Photon Source Project (APS) generate x-ray beams with very high heat loads and heat flux levels. The front-end and beamline components are required to sustain total heat loads of 5 to $15 \mathrm{~kW}$ and heat flux levels exceeding $400 \mathrm{~W} / \mathrm{mm}^{2}$. Grazing geometry and enhanced heat transfer techniques are used in the design of such components to reduce heat flux levels below the $30 \mathrm{~W} / \mathrm{mm}^{2}$ level, which is sustainable by the special copper materials routinely used in the component design. Although the resulting maximum surface temperatures can be sustained, the structural stresses and the fatigue issues remain viable concerns for the copper, particularly under brazing or bonding of the parts. Brazing and bonding are almost always utilized in the design of the components, and the drastically lowered yield stress of the annealed copper subjected to bonding temperatures above $400^{\circ} \mathrm{C}$ is a real concern. Such materials with reduced post-bonding stress levels easily reach yield point under thermal stresses during ordinary use on the beamline. The resulting plastic deformation in each load cycle may cause low-cycle-fatigue problems. The two common copper materials are OFHC and Glidcop. This paper critically reviews the available literature for low-cycle-fatigue properties of OFHC at the elevated temperatures typically found in synchrotron operations. The high vacuum 


\section{DISCLAIMER}

Portions of this document may be illegible electronic image products. Images are produced from the best available original document. 
environment seems to help significantly. Results indicate that components can be designed with better safety margins than appears to be the case using unscrutinized thermophysical property data. After examining the low-cycle-fatigue behavior of OFHC, analyses and evaluation of the life cycle number and crack propagation rate were performed based on data available in the literature and recommendations are made with respect to the safe use of OFHC in high-heat-load beamline components design.

\section{Low-cycle-fatigue behavior of OFHC}

There are three stages of the fatigue process under cyclic loading. The first stage is called cyclic hardening/softening. The material will soften or/and harden depending mainly on the original state of the material and the stress amplitude. This stage is characterized by changes in the substructure within the whole volume of the loaded metal. The second stage is microcrack nucleation, which takes place in a small part of the total volume at the surface layer. A common reason for all types of nucleation is stress concentration in the surface layer. The third stage is crack propagation that may lead to final failure. The main factor in crack propagation is the highly concentrated cyclic plastic deformation within the plastic zone at the crack tip.

For annealed OFHC, the first stage is about $3 \%$ of the total life cycle, that is, within $3 \%$ of total fatigue cycles, the stress strain curve will be stabilized or saturated as shown in Fig. 1 for polycrystalline copper. After fatigue hardening/softening is completed, the cycled metal exhibits a steady-state behavior. The stress strain curve is called a cyclic stress-strain curve, which represents one of the most import quantitative fatigue characteristics of a material. Fatigue hardening/softening constitutes only a small fraction of the total number of cycles to fracture. The conventional tensile stress-strain curve is the material response in the first half cycle. While the cyclic stress-strain curve is the response during saturation. If the cyclic stress-strain curve lies above the monotonic one, the material hardens; if it is below, the material softens. For the annealed OFHC, it becomes a fatigue-hardened material, as shown in Fig. 1.

Fatigue cracks always nucleate from the free surface of cyclically loaded metals. Nucleation occurs at positions where the cyclic-plastic deformation is higher than average. There are three 
types of nucleation sites: fatigue slip bands, grain boundaries, and surface inclusions. The nucleation stage ends in the formation of surface microcracks. In the course of further cyclic loading, the microcracks grow and link together. With increasing length, the growing cracks leave the original slip planes and tend to propagate perpendicular to the stress axis. Crack propagation ends by the fracture of the remaining cross section.

To evaluate the life cycles of a material, a stress vs. the number of cycles to failure relation is used, that is, the $\mathrm{S} / \mathrm{N}$ curve is widely used for the high number of cycles to fracture region. In the region of low number of cycles to fracture (about $10^{2}<N_{f}<10^{5}$, where $N_{f}$ is the number of cycles to failure), another fatigue-life curve, bàsed on the plastic-strain amplitude, is available. This curve is called the Manson-Coffin relation. Sometimes, a curve based on total strain and cycle numbers is used. Fatigue-life curves in both low-cycle and high-cycle region (i.e., the $\mathrm{S} / \mathrm{N}$ curve, the Manson-Coffin curve, and the curve of total strain vs. cycles number) can be mutually transformed with the help of the cyclic stress-strain curves.

Figure 2 shows the Mason-Coffin curves for copper, a-brass, and three steels [1]. One can use cyclic stress-strain curves to do the structural analysis and then use plastic strain from the analysis and the Mason-Coffin curve to predict the life cycle of the structure.

Many factors have an influence on the fatigue life, such as temperature, environment, grain size, etc. Temperature is the most important external parameter influencing fatigue life. According to Klesnil and Lukas [1], fatigue is conditioned by cyclic plastic deformation in all its stages. Processes of plastic deformation are generally temperature-dependent; for this reason, temperature influences all stages of fatigue. At a given temperature, the cyclic plasticity is determined by two parameters, plastic-strain amplitude and stress amplitude, and their relationship. It is just this cyclic stress-strain response that is very strongly temperature-dependent and that offers a basis for interpretation of fatigue-life data obtained under different regimes of cycling. Earlier experimental results on $\mathrm{S} / \mathrm{N}$ curves show that the fatigue strength decreases with increasing temperature, provided no phase or morphological changes occur. This is valid throughout a broad temperature range from liquid helium temperature to creep temperature. However, experimental results of the 
influence of temperature on Mason-Coffin curves do not provide such a simple picture. In many cases, the Manson-Coffin curves are temperature-independent. In other cases, they are temperature-dependent in the same way as the $\mathrm{S} / \mathrm{N}$ curves are.

The temperature dependence of the Manson-Coffin curves at high temperatures diminishes when cycling is performed in vacuum. Both the crack density and crack length of dominate cracks increase more quickly in air than in vacuum resulting in one order-of-magnitude higher fatigue life in vacuum as shown in Fig. 3 [2] for OFHC. Crack nucleation enhancement and acceleration of microcrack growth in the air is apparent. The enhancement of the crack nucleation rate in air was ascribed to oxide scale cracking. The higher number of microcracks in air contributes to crack coalescence and early fracture [3]. It was found that crack initiation in vacuum was as rapid as in air, but the cracks took longer to propagate, so the role of oxygen must involve absorption on the crack surfaces and possibly the lowering of the surface energy [4].

The reason why the Manson-Coffin curve for some materials is temperature dependent is that, besides enhanced diffusion at high temperatures, a most obvious change occurs from transcrystalline to intercrystalline crack nucleation and propagation. Intercrystalline crack propagation, which has been fractographically well proven at higher temperature, is faster than transcrystalline propagation, and thus it shortens the total fatigue life of strain-controlled cycled specimens. This is supported further by the formation of creep cavities, oxides, and precipitates at grain boundaries. The transition from transcrystalline to intercrystalline crack propagation is, moreover, strongly enhanced by the presence of an oxidation environment. In vacuum, the crack propagation at high temperature remains primarily transcrystalline; while in air, the crack propagation (as well as nucleation) is almost exclusively intercrystalline. Thus, the reason for the strong temperature dependence of the Manson-Coffin curves in air is due mainly to oxidation, which changes the mechanism of crack nucleation and propagation [1].

Generally, the fatigue strength is raised as the grain size is reduced. It is assumed that this arises because the grain boundaries are good obstacles to the propagation of a fatigue crack as they are for the propagation of a brittle crack. Large grain size can be the result of the annealing 
process, for example, a brazing process. On the other hand, cold work or prestrain makes the grain size smaller.

In summary, after annealing by a brazing process, the yielding stress of OFHC reduces to about 30-60 MPa. However, due to cyclic hardening, the cyclic stress-strain curve can be increased to a higher level (within about $3 \%$ of the total number of cycles). The yielding stress also increases accordingly. Therefore, the monotonic stress-strain curve cannot be used in the analysis and evaluation of an OFHC structure.

\section{Analysis and life cycle number evaluation of an APS slit}

Thermal and thermal stress analyses have been performed on a slit from both APS wiggler and undulator beamlines. The maximum temperature and maximum thermal stress are about 120 ${ }^{\circ} \mathrm{C}$ and $120 \mathrm{MPa}$, respectively. One can evaluate the life cycle number based on these analyses and the existing experimental data.

First, a simplified model is analyzed by conservatively assuming that the structure is fully constrained in the heated part. The total thermal strain in the structure is

$$
\varepsilon_{t}=\alpha \Delta \mathrm{T}=17 \times 10^{-6} \times 120=2.04 \times 10^{-3} .
$$

From Figure 4 (from Liu et al. [5]), it can be seen that the cycle number to failure corresponding to this strain is about $2 \times 10^{4}$. Note that the experimental data from Liu et al. [5] were based on annealed $\mathrm{OFHC}$ at $300^{\circ} \mathrm{C}$ in high vacuum, which is very close to the APS slit situation except that the maximum temperature of the slit is only $120^{\circ} \mathrm{C}$. Because $120 \mathrm{MPa}$ maximum stress on the OFHC is derived from a linear analysis, while the yielding stress is 100 MPa according to the cyclic stress-strain curve in Figure 1. The actual stress should be less than the value determined from elastic analysis due to plastic deformation. From a strain corresponding to the fictitious elastic stress $120 \mathrm{MPa}$ and the cyclic stress-strain curve, we find that the maximum stress is about $110 \mathrm{MPa}$. From the $\mathrm{S} / \mathrm{N}$ curve in Fig. 3, more than $10^{6}$ cycles to failure in vacuum at room temperature are possible.

At the stress level of $110 \mathrm{MPa}$, the elastic strain can be calculated as 
$\varepsilon=\frac{\sigma}{\mathrm{E}}=\frac{110 \times 10^{6}}{117 \times 10^{9}}=1.0 \times 10^{-3}$

The difference between total strain and elastic strain is plastic strain:

$\varepsilon_{a p}=2.04 \times 10^{-3}-1.0 \times 10^{-3}=1.04 \times 10^{-3}$.

Using the Manson-Coffin curve from Fig. 2, one obtains a cycle number to failure of about $2 \times 10^{4}$. However, it should be noted that Fig. 2 shows the test data under normal conditions (i.e., in air). The value is expected to be about one order of magnitude higher in vacuum according to the experimental data given above. That is to say, the number should be about $2 \times 10^{5}$ according to Fig. 2. By using the $\mathrm{S} / \mathrm{N}$ curve from Fig. 5 , the cycle number to failure is about $3 \times 10^{4}$ at a stress level of $110 \mathrm{MPa}$ based on the test data on $\mathrm{OFHC}$ annealed at $800^{\circ} \mathrm{C}$. Homma et at. [2] also tested $\mathrm{OFHC}$ in vacuum, annealed at $800^{\circ} \mathrm{C}$. Their test data show that the cycle number to failure at a stress level of $120 \mathrm{MPa}$ is about $1 \times 10^{6}$. More data are given in reference [6], from which one can get similar results.

In summary, the cycle number to failure of the slit due to thermal stress varies from $2 \times 10^{4}$ to $1 \times 10^{6}$, according to different sources. The smaller value corresponds to test data performed at 300 ${ }^{\circ} \mathrm{C}$ in high vacuum on a regular ASTM fatigue specimen [5]. The larger value is from the test data [2] performed at room temperature in vacuum. Because the APS slit operates under the same circumstance but with a temperature between the above two cases, it can be estimated that the current slit design can survive about $2 \times 10^{4}$ to $1 \times 10^{6}$ load cycles without failure.

\section{The APS photon shutter with a penny-shaped crack}

The APS photon shutter is made of an OFHC base plate that has seven holes for cooling and a face plate made of Glidcop. Two plates are brazed together. Due to the process of brazing, penny-shaped cracks may be postulated to form at the interface. By chance, if a penny-shaped crack is assumed to be just under the footprint of the beam, the possible propagation of the crack under thermal loading becomes a real concern. A penny-shaped crack can be modeled as in Fig. 6 a). The material properties at the two sides of the crack are different. Glidcop has a Young's modulus of $130 \mathrm{GPa}$; while OFHC has a Young's modulus of $117 \mathrm{GPa}$. 
The structure is loaded by thermal flux across the crack plane from the Glidcop plate to the OFHC plate. At normal working conditions, the interface experiences a temperature of $100^{\circ} \mathrm{C}$. Because of different material properties, the thermal stresses at the two sides of the interface are also different. The difference of the thermal stresses in the two different materials will result in shear stress in the bounding interface. The penny-shaped crack will be subjected to shear stress. Depending on the relative locations of the beam and the penny-shaped crack, one can postulate two load cases for the crack, as depicted in Figs. $6 \mathrm{~b}$ ) and $6 \mathrm{c}$ ). The maximum possible shear stress can be estimated conservatively as:

$$
\begin{aligned}
\tau_{\max } & =\Delta T \alpha\left(E_{2}-E_{1}\right)=100 \times 17 \times 10^{-6} \times 13 \times 10^{9} \\
& =22.1 \times 10^{6} \mathrm{~Pa}=22.1 \mathrm{MPa} .
\end{aligned}
$$

The stress intensities for the two cases can be found in reference [7]. For case 1

$$
K_{2}=\frac{1}{2} \tau a^{1 / 2},
$$

and for case 2,

$$
K_{2}=\frac{4}{(2-v) \pi} \tau a^{1 / 2} \cos (\theta-\beta) .
$$

The maximum value of Eq. (2) is

$$
K_{2}=\frac{4}{(2-v) \pi} \tau a^{1 / 2}
$$

Equation (3) results in a larger value than equation (1). Hence, only the $\mathrm{K}_{2}$ value from equation (3) need be checked for the worst case. Assuming that a crack has a radius a $=1 \mathrm{~mm}$, one can calculate $K_{2}$ from equation (3):

$$
K_{2}=0.75 \times 22.1 \times \sqrt{0.001}=0.524 \mathrm{MPa} \sqrt{m} .
$$

This value should be compared with the material property $\mathrm{K}_{2 c}$. In the literature, the following data are found for copper:

$$
K_{1 c}=110 \mathrm{MPa} \sqrt{\mathrm{m}} \text {. }
$$

From the energy point of view, one can assume $K_{1 c}$ and $K_{2 c}$ to be approximately the same. Comparison of the stress intensity with the material data shows that the stress intensity is much smaller than the data for failure of the material. 
The crack growth speed can be calculated also. From Pook [8], the $\Delta \mathrm{K}_{\mathrm{c}}$ for copper at a speed da/dN $=10^{-6} \mathrm{~mm} / \mathrm{c}$ is $4.3 \mathrm{MPa} \sqrt{\mathrm{m}}$. Because the thermal load on the APS shutter starts from zero, $\Delta \mathrm{K}$ is same as $\mathrm{K}_{2}$ :

$$
\Delta K=K_{2}=0.524 M P a \sqrt{m} .
$$

This value is also much smaller than $\Delta \mathrm{K}_{\mathrm{c}}$. That is, the crack will propagate at a speed less than $10^{-6} \mathrm{~mm}$ per cycle.

Also, from Pook [8], the threshold value $\Delta \mathrm{K}_{\mathrm{th}}$, below which there is no observable crack growth, is $2.7 \mathrm{MPa} \sqrt{m}$. Thus, one has

$$
\Delta \mathrm{K}<\Delta \mathrm{K}_{\mathrm{th}},
$$

which means that, under normal work conditions, a preexisting penny-shaped crack of radius 1 $\mathrm{mm}$ in the brazing boundary will not develop or propagate due to the shear stress in the interface caused by different material properties at the two sides.

For a very conservatively chosen 4-mm radius penny-shaped crack, the temperature field can no longer be assumed to be uniform; that is, there is a temperature difference in the normal direction of the crack. This temperature difference from a finite element thermal analysis is shown to be about $20^{\circ} \mathrm{C}$. The maximum shear stress can be calculated as:

$$
\begin{aligned}
\tau_{\max } & =T_{2} \alpha E_{2}-T_{1} \alpha E_{1} \\
& =105 \times 17 \times 10^{-6} \times 130 \times 10^{9}-85 \times 17 \times 10^{-6} \times 117 \times 10^{9} \\
& =63 \times 10^{6} \mathrm{~Pa}=63 \mathrm{MPa} .
\end{aligned}
$$

The $\mathrm{K}_{2}$ value is

$$
K_{2}=0.75 \times 63 \times \sqrt{0.004}=3 \mathrm{MPa} \sqrt{m},
$$

which is larger than the threshold $\Delta \mathrm{K}_{\mathrm{th}}$, however less than the value $\Delta \mathrm{K}_{\mathrm{c}}$. This leads to the result that a preexisting 4-mm radius penny-shaped crack will grow; however, the growth rate will be less than $10^{-6} \mathrm{~mm}$ per load cycle. Therefore the total growth during the life cycle $\left(2 \times 10^{4}\right)$ will not be more than $0.02 \mathrm{~mm}$.

\section{Conclusion}

Due to the brazing process, the yielding stress of OFHC reduces to about 30-60 MPa. Under cyclic load conditions, the cyclic stress-strain curve can be increased to a higher level (within about 
$3 \%$ of the total number of cycles). The yielding stress of the OFHC also increases accordingly giving a higher low-cycle-fatigue number for components made of OFHC used in synchrotron radiation facilities. High vacuum can also increase the low-cycle-fatigue life number of OFHC by one order of magnitude.

Analyses and evaluations on a simplified model revealed that the APS slit can survive $2 \times 10^{4}$ to $1 \mathrm{X} 10^{6}$ load cycles without failure. A preexisting $1 \mathrm{~mm}$ radius penny-shaped crack in the brazing boundary will not grow due to the shear stress in the interface caused by different material properties at two sides. A very conservatively postulated 4-mm radius penny-shaped crack will grow, but the growth rate is less than $10^{-6} \mathrm{~mm}$ per load cycle.

\section{Acknowledgments}

The authors are grateful to Dr. S. Majumdar for this comments and suggestions in the course of this work and to S. Picologlou for her effort in editing the paper. This work is supported by the U.S. Department of Energy, BES-Materials Sciences, under contract no. W-31-109-ENG-38.

\section{References}

1. M. Klesnil and P. Lukas, Fatigue of Metallic Materials, Elsevier Scientific Publishing Co. New York, 1980.

2. T. Homma et al., Effect of grain size and zinc concentrations on fatigue strength of oxygen-free high-conductivity copper and alpha-brass, Kozangakubu Kenkyu Hokoku, Vol. 12, pp. 19-26, 1991.

3. J. Polak, Cyclic Plasticity and Low Cycle Fatigue Life of Metal, Elsevier Scientific Publishing Co., New York, 1991.

4. R. Honeycombe, The Plastic Deformation of Metals, Edward Arnold Ltd., Great Britain, 1968.

5. K. C. Liu and C. M. Loring, Jr, J. Nucl. Materials, 122\&123, 783-788, 1984.

6. R. Reed and R. Mikesell, Low Temperature Mechanical Properties of Copper and Selected Copper Alloys, National Bureau of Standards Monograph 101, Dec. 1967. 
7. M. K. Kassir and G. C. Sih, Three-dimensional crack problems: a new selection of crack solutions in three-dimensional elasticity, Noordhoff International Publishing, Leyden, 1975.

8. L. Pook, Theoretical background to elastic fracture mechanics.

9. Bullen, Head, and Wood, Proc. R. Soc., A216, 332, 1953.

10. T. Homma et al., Effect of grain size and atmospheric environment on fatigue strength of oxygen-free copper, Kozangakubu Kenkyu Hokoku, Vol. 11, 23-30, 1990.

\section{DISCLAIMER}

This report was prepared as an account of work sponsored by an agency of the United States Government. Neither the United States Government nor any agency thereof, nor any of their employees, makes any warranty, express or implied, or assumes any legal liability or responsibility for the accuracy, completeness, or usefulness of any information, apparatus, product, or process disclosed, or represents that its use would not infringe privately owned rights. Reference herein to any specific commercial product, process, or service by trade name, trademark, manufacturer, or otherwise does not necessarily constitute or imply its endorsement, recommendation, or favoring by the United States Government or any agency thereof. The views and opinions of authors expressed herein do not necessarily state or reflect those of the United States Government or any agency thereof. 


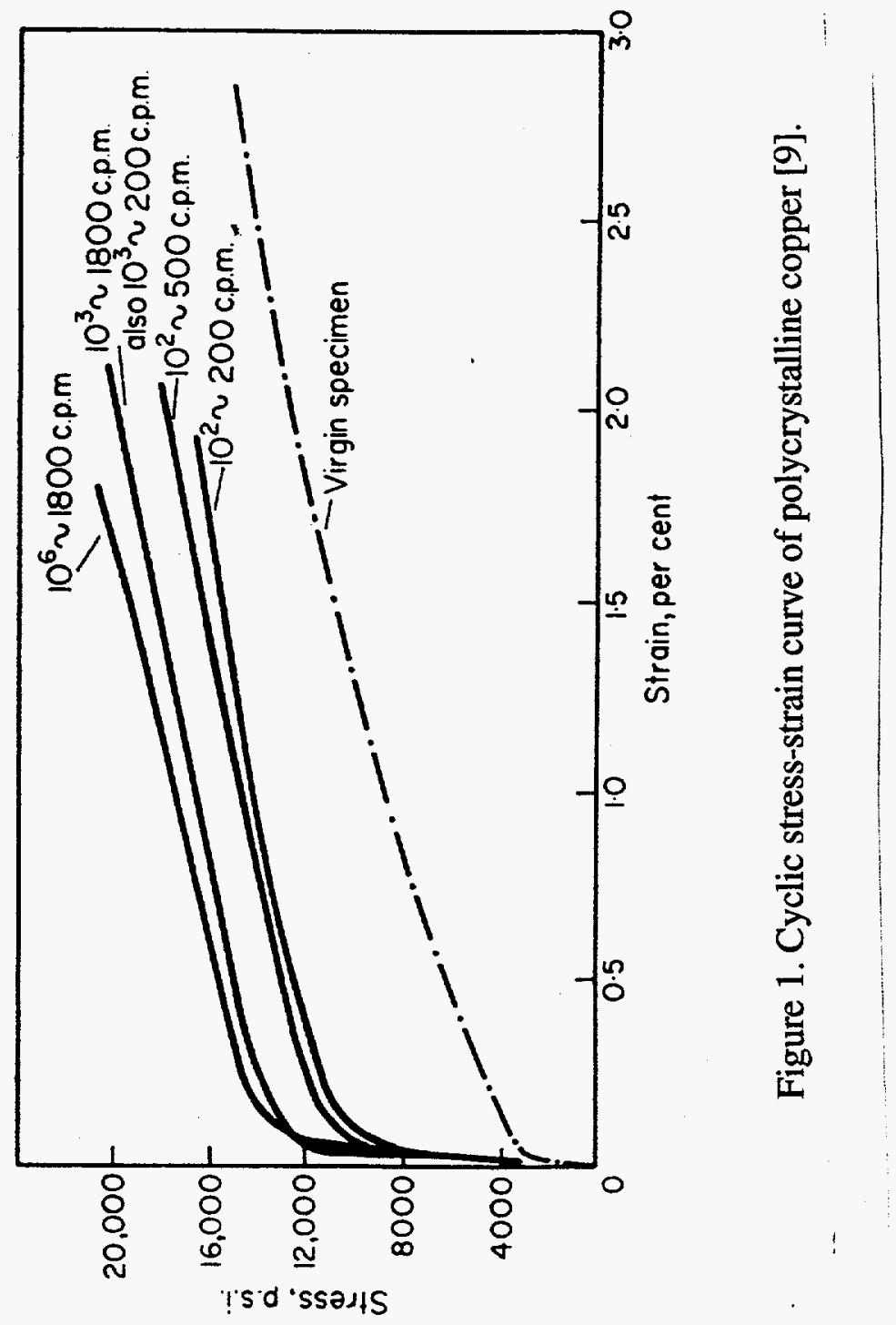




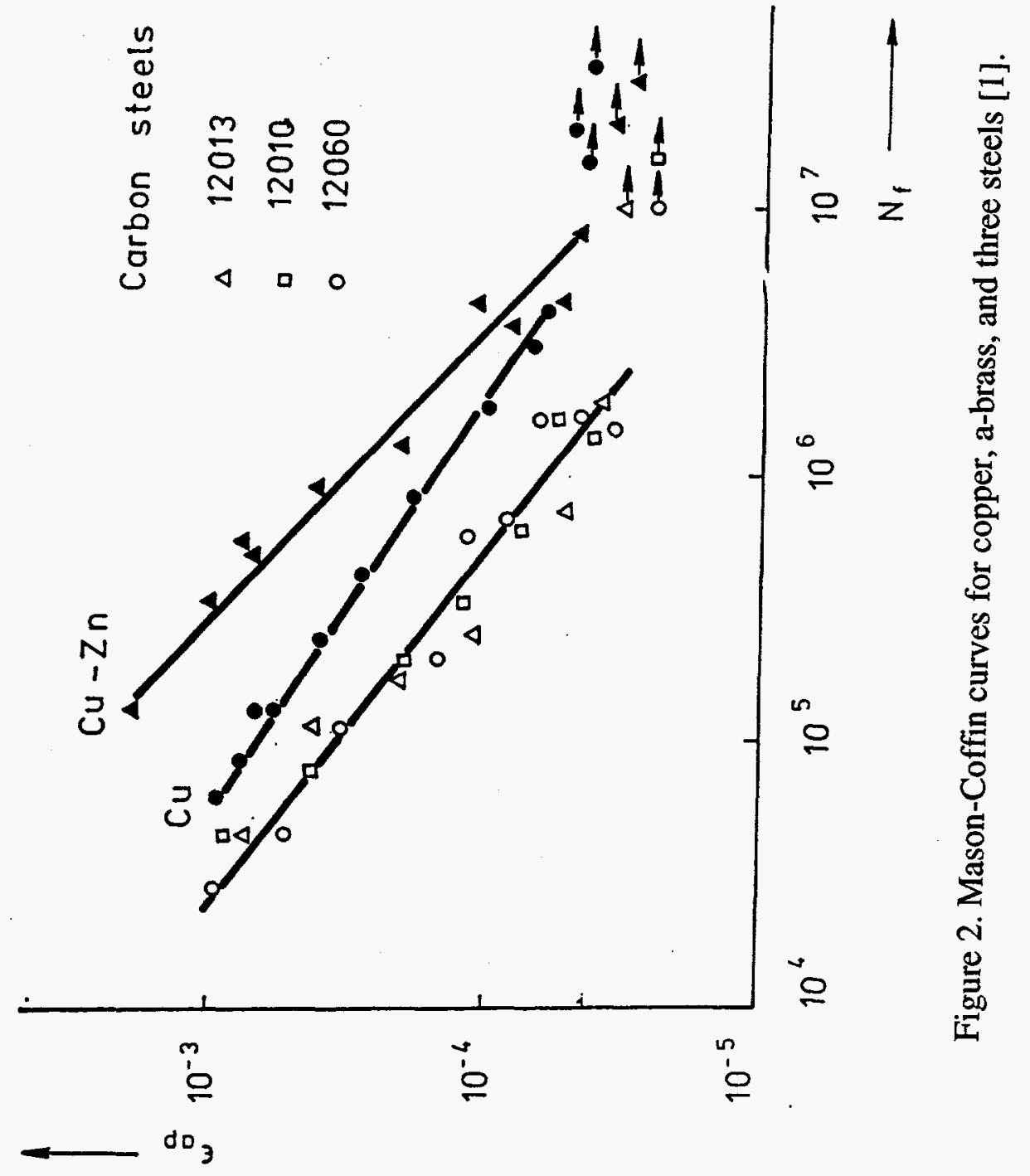




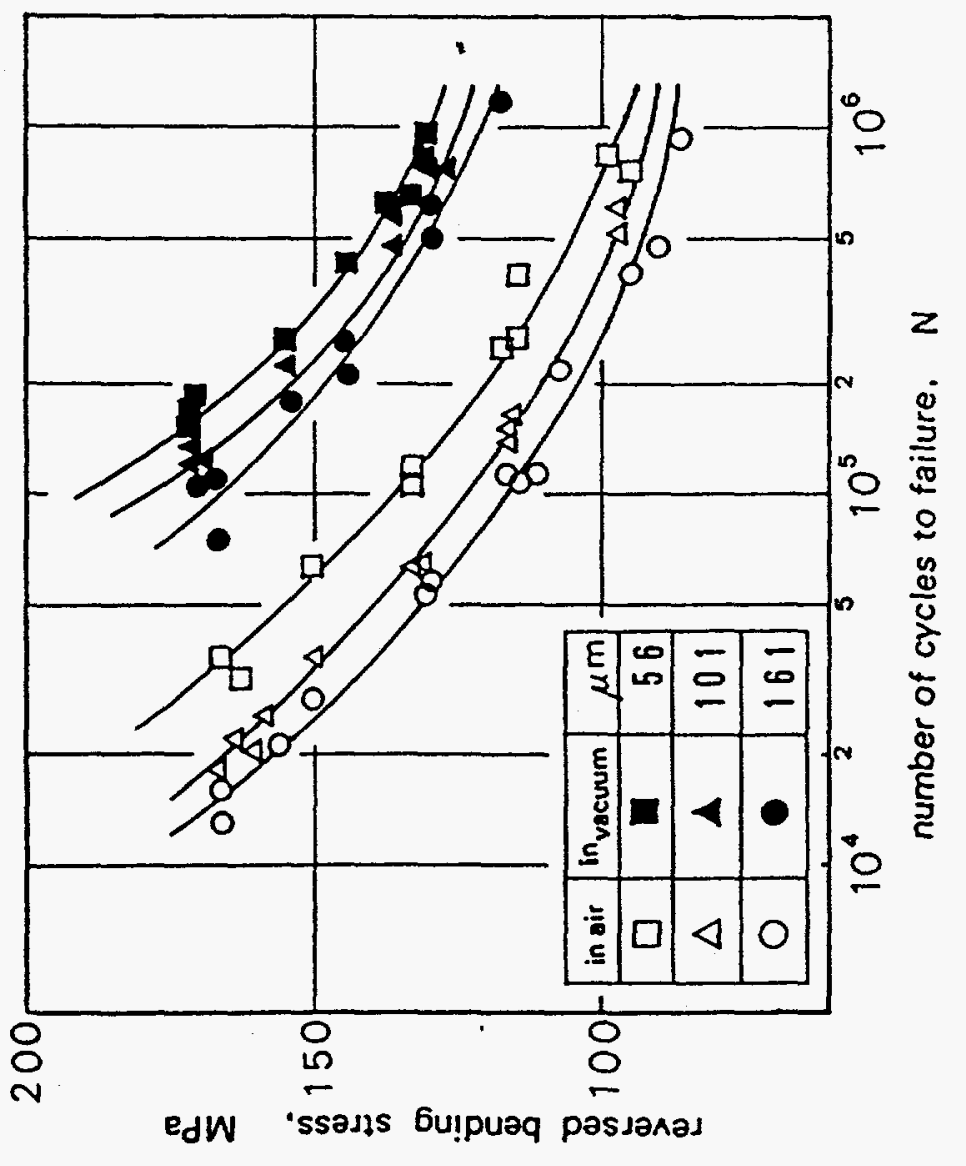

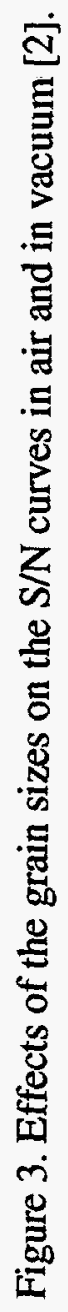




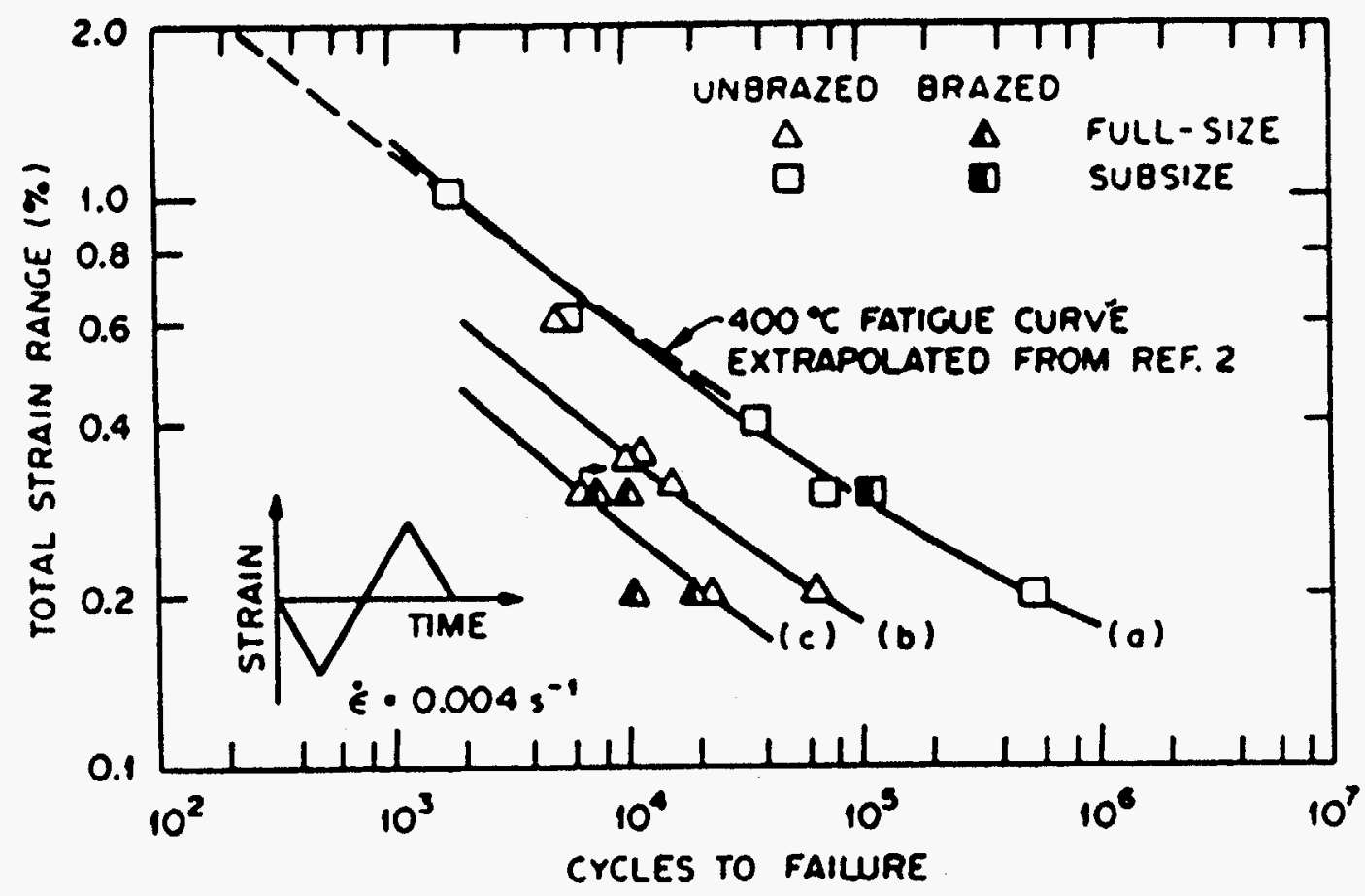

Figure 4. Total strain as a function of cycles to failure for $\mathrm{OFHC}$ tested at $300^{\circ} \mathrm{C}$ in vacuum [5]. 


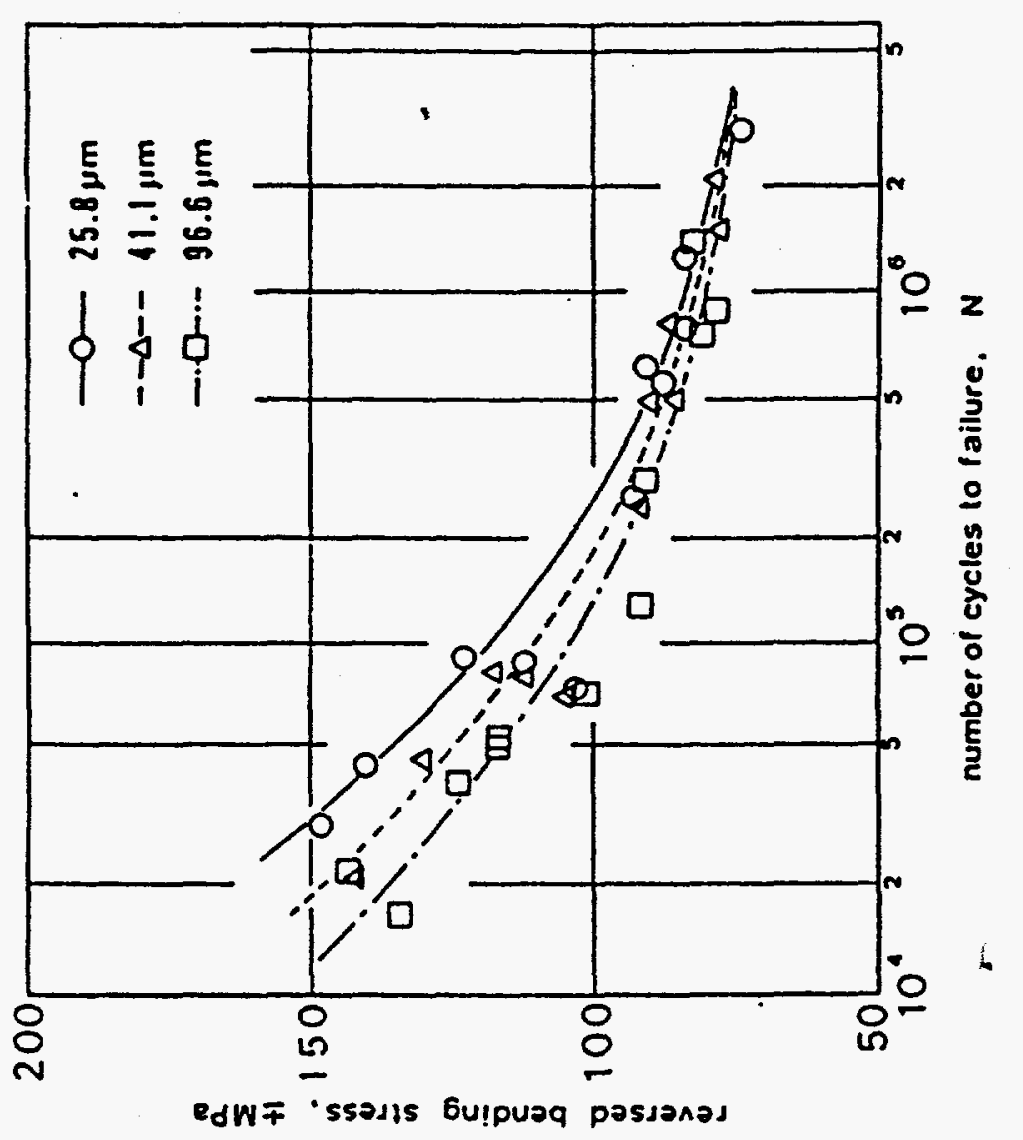

官 

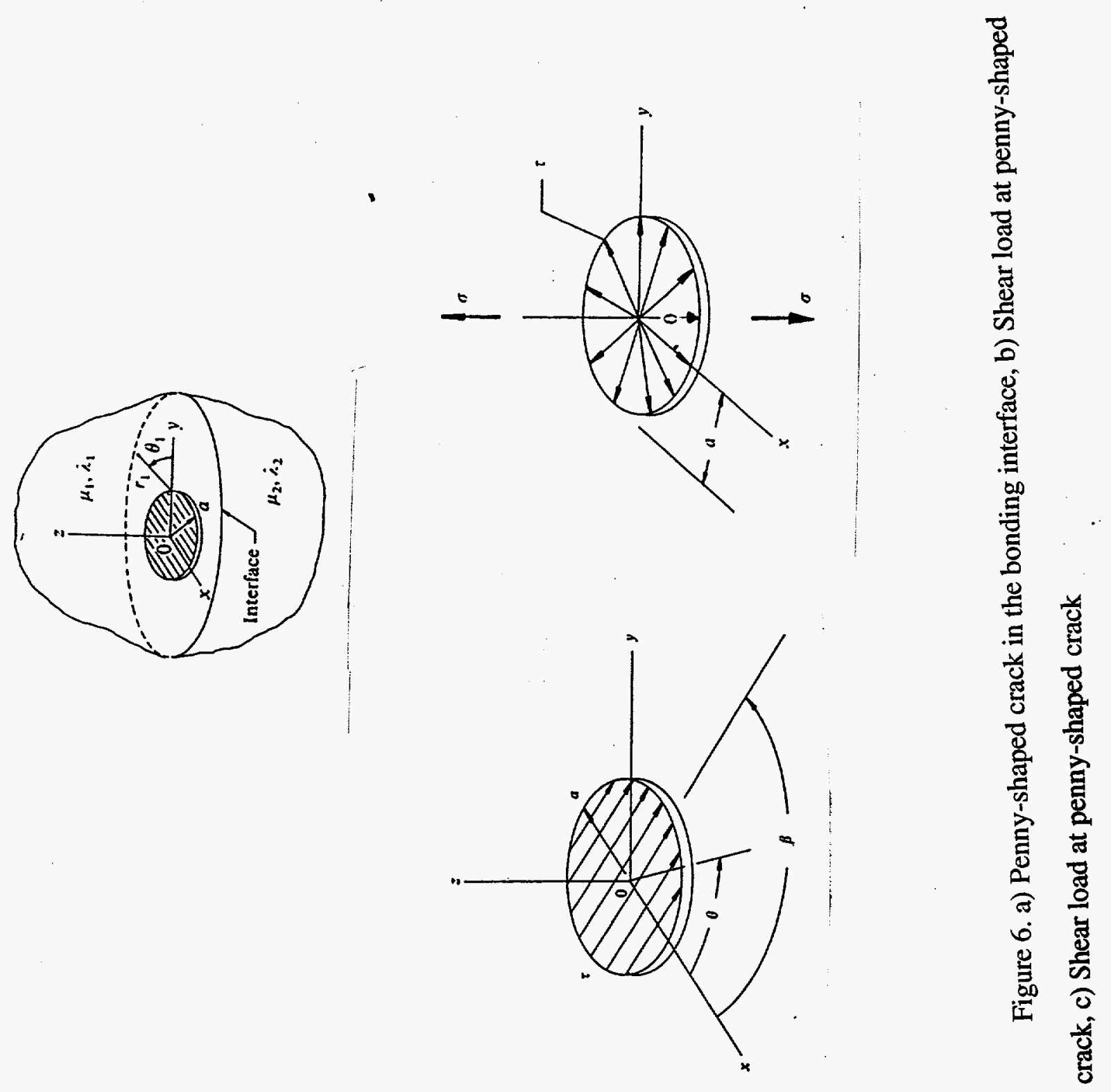